\title{
ECOLOGIA DO CORPO CORAÇÃO MENTE ESPÍRITO: TECENDO REFLEXÕES ACERCA DE INTERCULTURA E BEM VIVER
}

Nadir Esperança Azibeiro ${ }^{1}$

\begin{abstract}
Resumo: Este artigo tece reflexões em torno do Bem Viver (Sumak Kawsay), que concebe o ser humano integrado ao Cosmos, como uma de suas partes. Propondo respeito à dignidade de todos os seres, em complementariedade, aproxima-se do que Maturana denomina Matrístico. Manifesta, ainda, conexões com as propostas da Ecologia Profunda, da Ecopsicologia, do Ecofeminismo, da Psicologia Transpessoal. Transformando-se de ponto de partida em objetivo de vida, instiga a uma perspectiva intercultural, a uma educação dialógica, impulsionando experiências que manifestem um modo de ser eco-lógico, contrapondo-se ao ego-lógico próprio da cultura ocidental moderna. Desse modo, abrem-se outras possibilidades de atualizar, em cada aqui e agora específico, a possibilidade real de desconstrução de subalternidades.
\end{abstract}

Palavras-chave: Bem Viver; Ecologia do CorpoCoraçãoMenteEspírito; Educação Dialógica; Intercultura; Desconstrução de Subalternidades.

\section{ECOLOGÍA DEL CUERPO CORAZÓN MENTE ESPÍRITU: TECENDO REFLEXIONES ACERCA DE INTERCULTURA Y BUEN VIVIR}

Resumen: Este artículo teje reflexiones acerca del Buen Vivir (Sumak Kaway), que considera al ser humano integrado en el Cosmos, como una de sus partes. Propone el respeto a la dignidad de todos los seres, en complementariedad, enfoque que Maturana denomina Matrístico. Expresa, además, las conexiones a las propuestas de la Ecología Profunda, Ecopsicología, Ecofeminismo y de la Psicología Transpersonal. Convirtiéndose de punto de partida al objetivo de la vida, instiga una perspectiva intercultural, la educación dialógica, estimulando experiencias que expresan una forma de ser eco-lógico, en contra del ego-lógico, propio de la cultura occidental moderna. De esta manera, se puede abrir otras posibilidades para actualizar en cada aquí y ahora específicos, la posibilidad real de deconstrucción de subalternidades.

Palabras clave: Buen Vivir. Ecologia del CuerpoCorazónMenteEspíritu. Educación Dialógica. Interculturalidad. Deconstrucción de Subalternidades.

\section{À Guisa de alinhavos}

Teorias são ferramentas para pensar. ${ }^{2}$ Ao longo da História, têm sido utilizadas como formas de demarcação de territórios, ou campos de força - instrumentos de poder-dominação. Mesmo quando se propõe às libertações, acabam se constituindo em justificativas para 
subjugações e exclusões. Talvez por isso minha quase fascinação por encontrar - e elaborar teorias que quebrem padrões, que incluam, que instiguem conexões.

Estas reflexões se alinhavam como uma genealogia, ou talvez como uma arqueologia, retalhos de múltiplos ditos e feitos, em busca de pensares e fazeres que acolham e dialoguem³. O fio que trabalhará e conectará todos esses retalhos é a opção ético-político-epistemológica pela desconstrução de subalternidades. ${ }^{4}$

Como pensar o Bem Viver - e possibilidades de uma educação que leve a ele? Essa questão vem me acompanhando a vida toda, formulada e reformulada inúmeras vezes a partir dos contextos em que fui me inserindo e de diálogos encetados, muitas vezes estabelecidos por longa data, dando início a outros diálogos e a muitos aprendizados.

Sim. Porque essa é uma convicção antiga: a educação só pode ser dialógica. ${ }^{5}$ Aprendi isso a partir de minha própria experiência e o confirmei ao longo dos anos com a prática e a reflexão sobre ela.

Estando no ginásio ${ }^{6}$ no início dos anos 1960, anos de muita efervescência e rebeldia, encontrei professoras e professores que se dispuseram a experimentar novas formas de ensinaraprender. Só algum tempo depois fiquei sabendo que já eram buscas de um trabalho interdisciplinar, que chegava mesmo a transcender os limites das disciplinas específicas, levando-nos a um entendimento de nós mesm@s e da realidade que percebia e incluía diferentes e diferenças, sem discriminações ou exclusões.

Antes que eu terminasse o ginásio tudo isso foi bruscamente cortado. Era 1964. A ruptura, que sentimos na pele, passando abruptamente de uma educação dialógica a um ensino disciplinar, beirando ao autoritário, só fez com que se firmasse em mim a convicção de que, não sendo dialógica, qualquer proposta de educação acaba por se transformar num meio de colocar numa forma, de enquadrar nos padrões estabelecidos, de cercear a criatividade e amortecer as potencialidades.

Muitas pessoas morreram naquela época. $\mathrm{Eu}$ fui uma das sobreviventes. $\mathrm{E}$ ainda durante os anos da ditadura acabei tendo contato com a proposta de educação dialógica e libertadora de Freire. No curso de Pedagogia conheci também Montessori, Makarenko, Dewey, Bruner, Piaget, Freinet, Illich, Rogers, Neil, dentre outr@s. Grandes distinções eram feitas entre as propostas liberais e as propostas progressistas, libertárias, libertadoras. Ao invés de me ater a essas distinções, fui tentando analisar e experimentar cada uma delas, 
buscando ferramentas para compor e praticar uma educação dialógica, que não acirrasse exclusões, mas pudesse contribuir com a inclusão, com a consciência das diferenças, produzidas histórica e culturalmente como hierarquias. Que pudesse contribuir com a desconstrução de subalternidades.

Tomei então contato com a Complexidade e a Transdisciplinaridade como propostas para perceber os pares de opostos não como dualidades, mas como complementariedades, capazes de produzir rupturas e deslocamentos, com o desvelamento dos jogos de poder intrínsecos às relações culturalmente estabelecidas. Jogos de poder que produzem continuamente diferenças. Assim descobri a Intercultura e cheguei ao Pensamento Fronteiriço, como possibilidade de esgarçamento dos paradoxos para que os processos de subalternização - não apenas os que aconteceram historicamente - mas os que continuam a acontecer, contínua e cotidianamente - viessem à tona e pudessem ser, imediatamente ou paulatinamente, desconstruídos.

Nesse processo fui desenvolvendo e me envolvendo com experiências educativas em sala de aula, em grupos de pesquisa e extensão, em comunidades de periferia, com grupos de multiplicador@s, ${ }^{7}$ com a formação de educador@s, dentro e fora da Academia. Fui me inventando como educadoraterapeuta. Participei também, desde sua criação, nos anos 1990, no Núcleo MOVER, experimentando as possibilidades e limites das várias propostas de Educação Intercultural.

Quando recebi a proposta de escrever um texto para esta publicação, pensei em compartilhar com vocês estas andanças teórico-práticas e alguns dos acontecidos que fui percebendo ao longo destes anos. Talvez possa voltar a trazer algum encantamento a quem se aventura por estas trilhas de pensar e tornar materialidade o Bem Viver.

Não pretendo aqui polemizar com nenhuma das escolas teóricas que trabalham a produção histórica das subalternidades. ${ }^{8}$ Meu interesse é compartilhar estudos, experiências, intuições que possam alargar as possibilidades de desconstrução de subalternidades, ${ }^{9}$ desenvolvendo uma ecologia do corpo coração mente espírito.

\section{O Sumak Kawsay como ponto de início e de chegada}

Tomei contato com Sumak kawsay entre 2010 e 2011. Desenvolvia então um projeto de estudo e extensão a que chamávamos Grupo de Multiplicador@s, pois seu objetivo era 
encontrar fundamentos para continuar desenvolvendo propostas de ação e educação baseadas no diálogo, na interculturalidade, no respeito, na cooperação, no cuidado com a Vida, na desconstrução de subalternidades e multiplicar isso nas relações e fazeres múltiplos em que participávamos. Mencionei-o em publicação de 2012. ${ }^{10}$

Logo que tomamos contato com a Constituição do Equador nos impressionamos com a quantidade de sincronicidades com o que vínhamos estudando, criando, divulgando, vivendo. $^{11}$ pueblos,

RECONOCIENDO nuestras raíces milenarias, forjadas por mujeres y hombres de distintos

CELEBRANDO a la naturaleza, la Pacha Mama, de la que somos parte y que es vital para nuestra existencia,

INVOCANDO el nombre de Dios y reconociendo nuestras diversas formas de religiosidad y espiritualidad,

APELANDO a la sabiduría de todas las culturas que nos enriquecen como sociedad,

COMO HEREDEROS de las luchas sociales de liberación frente a todas las formas de dominación y colonialismo,

Y con un profundo compromiso con el presente y el futuro,

Decidimos construir

Una nueva forma de convivencia ciudadana, en diversidad y armonía con la naturaleza, para alcanzar el buen vivir, el sumak kawsay. ${ }^{12}$

O Sumak Kawsay concebe o ser humano como um dos integrantes do cosmos, ao lado de múltiplas outras formas de existência e de vida. Funda-se sobre a ideia do respeito e harmonia consigo mesm@, com cada outr@,com a Natureza.

Sumak kawsay, para os quechua, representa a plenitude da vida. Mas esse ideal de bem viver não está presente apenas na comunidade quechua. Na cosmovisão dos aymara, o Bem Viver traduz-se na expressão suma qamaña. O bem viver, para os povos aymara, guarda ainda intensa relação com a ideia dos guarani de vida harmoniosa (ñandareko), vida boa (teko kavi), terra sem males ${ }^{13}$ (ivi maraei), e caminho ou vida nobre (qhapaj ñan). Para os ashuar, da fronteira do Peru com o Equador, o Bem Viver se expressa como uma paz doméstica e uma vida harmoniosa (waras shiir) do mesmo modo que o querer uma vida melhor (küme mongen), dos mapuche. Expressões semelhantes são encontradas em praticamente todos os povos indígenas, não só na América Latina, mas em todas as culturas antigas do mundo.

Para Catherine Walsh, 
Em seu sentido mais geral o sumak kawsay [...] denota, organiza e constrói um sistema de conhecimento e vivência baseado na comunhão dos seres humanos e da natureza em uma totalidade de existência no espaço-tempo harmônico. Isto é, na necessária inter-relação dos seres, conhecimentos, lógicas e racionalidades de pensamento, ação, existência e vivência. Essa noção é parte e parcela da cosmovisão, cosmologia ou filosofia dos povos indígenas de Abya Yala. ${ }^{14}$

Nas palavras de Alberto Acosta, o Bem Viver "apresenta-se como uma oportunidade para construir coletivamente novas formas de vida". ${ }^{15}$

Com sua proposta de harmonia com a Natureza, reciprocidade, relacionalidade, complementariedade e solidariedade entre indivíduos e comunidades, com sua oposição ao conceito de acumulação perpétua, com seu regresso a valores de uso, o Bem Viver, uma ideia em construção, livre de preconceitos, abre as portas para a formulação de visões alternativas de vida (ACOSTA, 2016, p. 33). ${ }^{16}$

Esse anseio por formas mais integradas de Ser está presente não apenas nas Cosmologias de povos ancestrais. Manifesta-se, também, em pensares e experiências de pessoas e grupos em busca de alternativas ao modo de ser hegemônico na contemporaneidade. Para Gudynas:

Ainda que se possa achar a raiz desse conceito nas cosmovisões e práticas indígenas, ele pode ao mesmo tempo ser entendido como uma nova reformulação que, incorpora, ou ao menos se complementa, com noções não indígenas, provenientes da reflexão ocidental crítica (GUDYNAS, 2011, p.8).

Assim, a Ecologia Profunda, a Ecopsicologia e o Ecofeminismo são algumas das propostas teórico-práticas que se alinham com o conceito de Bem Viver. A Ecologia Profunda (Deep Ecology) é um conceito filosófico que considera que tudo o que faz parte da natureza deve ser respeitado, assim como deve ser garantido o equilíbrio da biosfera. O termo surgiu quando, em 1972, foi publicado o artigo "The shallow and the deep, long range ecology movement. A summary”, pelo filósofo e ambientalista norueguês Arne Naess (1912-2009).

A esse respeito, comenta Capra (1996, p. 17):

A ecologia rasa é antropocêntrica, ou centralizada no ser humano. Ela vê os seres humanos como situados acima ou fora da natureza, como a fonte de todos os valores, e atribui apenas um valor instrumental, ou de "uso", à natureza. A ecologia profunda não separa seres humanos - ou qualquer outra 
coisa - do meio ambiente natural. Ela vê o mundo, não como uma coleção de objetos isolados, mas como uma rede de fenômenos que estão fundamentalmente interconectados e interdependentes. A ecologia profunda reconhece o valor intrínseco de todos os seres e concebe os seres humanos apenas como um fio particular na teia da vida (CAPRA, 1996, p.17).

Apoiando-se e ao mesmo tempo distinguindo-se da Ecologia Profunda, o Ecofeminismo surgiu a partir da expressão usada por Françoise d'Eauboune, no livro "Le féminisme ou la mort”, publicado em 1974. Essa obra manifesta a existência de uma estreita relação entre o reconhecimento e valorização das mulheres - e do feminino - e o respeito e preservação da natureza.

A indiana Vandana Shiva é um dos nomes mais importantes do ecofeminismo. Em entrevistas e publicações, gosta de lembrar que o que se costuma chamar desenvolvimento "é um processo de mau desenvolvimento", "fonte de violência contra a mulher e a natureza em todo o mundo", "tem as suas raízes nos postulados patriarcais de homogeneidade, dominação e centralização, que constituem o fundamento dos modelos de pensamento e estratégias de desenvolvimento dominantes". Uma de suas principais preocupações gira em torno do modelo dominante de agricultura, que afeta o meio ambiente e a vida, em todo o planeta. Em entrevista publicada pelo Pelo Coletivo Huerquen, no Outras Palavras, Vandana Shiva relembra:

O ecofeminismo reconhece que a natureza não só está viva, mas também é a base de toda a vida e que somos parte dela. E compreende que nós, as mulheres, temos um grande potencial; mas um potencial diferente, não violento, não de dominação e morte, mas sim de cuidar e compartilhar. ${ }^{17}$

Apoiada em princípios semelhantes e integrando transdisciplinarmente Ecologia e Psicologia, a Ecopsicologia parte da percepção de que quanto maior a conexão com a Natureza, maior também a integração da pessoa com seu eu mais profundo. Marco Aurélio Bilibio, um dos pioneiros da Ecopsicologia no Brasil, em sua tese, afirma que a Ecopsicologia “desafia o viés antropocêntrico da Psicologia e propõe a existência de uma psicopatologia subjacente às relações entre ser humano e natureza" (CARVALHO, 2013, Resumo). E continua: "o foco central da Ecopsicologia são as relações do ser humano com a teia da vida" (ibid., p. 17).

Entendendo que uma das dimensões do Inconsciente Coletivo, como nomeado por 


\section{Jung, é o Insconsciente Ecológico, Bilibio explica:}

O centro da psique humana é essa camada, que guardaria o registro evolutivo de nossa espécie como parte da comunidade biótica [...]. Portanto, as conexões entre seres humanos e natureza não se restringem ao funcionamento orgânico, cujo princípio de existência é a sua total dependência das interações com o meio. Nossos corpos são estruturas de troca em ininterrupta relação com o meio, em cujas contínuas interações oscilam entre o equilíbrio, o desequilíbrio e o reequilíbrio, cuja cessação é a morte. Todavia, essas conexões são também psíquicas, na medida em que desde os primeiros hominídeos fomos construindo relações emocionais e cognitivas com o mundo que nos cerca [...] A identidade humana como espécie, portanto, não pode ser definida como se o mundo natural não existisse. Sendo uma dimensão essencial à humanidade, sua ausência constitui uma anomalia. Destituído da vivência sensível em que se reconhece um parceiro em constante relação com outras espécies, tal como expresso em mitos tribais, e construindo uma civilização autista em relação a elas, nos tornamos menos que humanos. Destituídos da capacidade de ler a natureza e suas forças para além do objetivismo científico e do utilitarismo empreendedor, tornamo-nos uma espécie cujas interações com o meio que nos originou tornaram-se destrutivas e de alto custo para as demais espécies (CARVALHO, 2013, p. 23-25).

Sendo assim, "o objetivo da Ecopsicologia é despertar o senso inerente de reciprocidade ambiental adormecido no Inconsciente Ecológico” (ibid. p. 52).

Embora se distingam em vários aspectos, essas propostas convergem no reconhecimento da interdependência de todos os seres e fenômenos, colocando o próprio planeta Terra como centro e admitindo o valor intrínseco de toda a natureza. Ressaltam a interrelação entre todas as formas de existência e de vida que compõem a Natureza: tudo está relacionado com tudo, em todos os pontos, em todos os tempos, em todas as circunstâncias.

Acosta acrescenta outras vozes que manifestam essa compreensão:

Entre as contribuições não indígenas, destacamos o ambientalista inglês James Lovelock, as biólogas norte-americanas Lynn Margulis e Elizabeth Sahtouris e o filósofo brasileiro José Lutzenberger. Esses pensadores caracterizaram a Terra - rebatizada como Gaia - como um superorganismo vivo, já nos anos 1970. Nessas visões, como ressalta o teólogo brasileiro Leonardo Boff, é preciso reconhecer o caráter inter-retro-conexões transversais entre todos os seres: tudo tem a ver com tudo, em todos os pontos e em todas as circunstâncias: é a relacionalidade do mundo indígena (ACOSTA, 2016, p. 136).

Caminhando nessa mesma direção, encontrei a Psicologia Transpessoal.

Reconhecendo a natureza multidimensional do ser humano e sua inserção numa dimensão 
cósmica mais ampla, propõe e estuda possibilidades de expansão da consciência, despertando para a unidade fundamental do Ser e do Cosmos.

Para Maslow, um de seus antecessores, ao negar a sua dimensão da transcendência, o ser humano cria doenças para si, para a sociedade e para o planeta. Ele afirma:

[...] a psicologia humanista foi uma transição, uma preparação para uma ainda mais elevada, quarta psicologia, transpessoal, trans-humana, centrada mais no cosmos que nos desejos e interesses humano (MASLOW, 1962, p. 128).

Levando a uma profunda conexão e integração pessoal e transpessoal, cósmica, fundamentando-se numa visão holística da realidade, a abordagem transpessoal assume, ao invés de excluir, tudo o que, em cada uma das outras abordagens, favorece a cura, o equilíbrio profundo do ser em harmonia consigo mesmo, com cada outr@, com a Natureza, com o Cosmos.

A Psicologia Transpessoal entende a consciência na sua dimensão mais ampla como Consciência de Unidade e o ser humano como um Ser Integral: um ser biológico, psicológico, social, ecológico, espiritual, cósmico. O prefixo trans significa mais além e, ao mesmo tempo, através de. Isto quer dizer que não se pretende na Psicologia Transpessoal uma evasão da dimensão pessoal, mas a busca da integração do transcendental no nível pessoal, através de práticas que facilitam a emergência de outros níveis de consciência. Estados de consciência que transcendem o ego, produzindo transformações e colocando o ser em sua dimensão de conexão com o Cosmos.

No Brasil, os pioneiros são Pierre Weil e Leo Mattos, que promoveram o Congresso de Belo Horizonte, em 1972, onde se assumiu como base da abordagem transpessoal a ampliação da consciência e o reconhecimento do ser humano como uma unidade bio-psicosocial-espiritual-ecológica.

Ao entender a espiritualidade como dimensão intrínseca do humano, distingue-a de qualquer tipo de prática ou filiação religiosa. As práticas espirituais favorecem a percepção e a concentração. Para Grof (1990, p. 88), o primeiro elemento de toda prática espiritual é penetrar no presente. A espiritualidade é justamente o estado de plenitude de presença, necessária para o equilíbrio, a partir da conexão consigo mesm@, com cada outr@, com a natureza, com o Cosmos.

Em vez de começar uma batalha de modelos, como se estes fossem ou pudessem ser

Revista Interinstitucional Artes de Educar. Rio de Janeiro, V. 4 N. 3 - pag 496-512 (out/2018 - jan/ 2019)

503

"Educação Intercultural: aprender com os povos originários do Sul a decolonizar a educação" DOI:10.12957/riae.2018.38220 
definitivos e completos, Grof (1998) instiga-nos, ao dizer que é muito mais sábio fazer o melhor que podemos para aprimorá-los e torná-los consoantes, mas deixar o campo aberto para surpresas e novas descobertas.

Para Wilber (1989, p. 20), as diversas escolas não são contraditórias, mas complementares. Ele afirma: o problema de decidir qual o 'melhor' enfoque é um falso problema, uma vez que cada uma dessas abordagens trabalha com um nivel diferente de consciência.

Ao efetuar a síntese das principais abordagens da consciência, acrescenta:

Fio-me de que, nas páginas seguintes, o leitor encontre espaço não só para o ego, o superego e o id, mas também para o organismo total, para o eu transpessoal e, finalmente, para a consciência cósmica fonte e sustentação de todos os demais (ibid., p. 5).

Ecologia do corpo, coração, mente, espírito. Assim passei a denominar a proposta educativaterapêutica que venho desenvolvendo. Quando comecei a falar na ominidimensionalidade $^{18}$ do ser humano, apenas começava a vislumbrar o alcance dessa proposta. Foi a partir da leitura de Capra $^{19}$ que comecei a elaborar uma perspectiva ecológica para o sersentirpensaragir. ${ }^{20}$ Cuidar do Ser, do que há de mais saudável em cada pessoa, grupo, situação. Ativar potenciais. "A gente se descobre capaz". ${ }^{21}$ Ubuntu, Sumak kawsay, Suma qamaña, Ivi maraei, Waras shiir, Küme mongen.

Sincronicidades. Encontros. Conexões. Nessa direção venho trabalhando, convicta de que o caminho pessoal e transpessoal é concomitante e complementar ao social e ao político. Assim se constitui a trilha ecológica. Essa é a profunda intuição do Bem Viver.

O Bem Viver, assim, supõe uma visão holística e integradora do ser humano na grande comunidade da Pachamama. Expandir as possibilidades de viver bem, em cada aqui e agora específicos, aumentando as possibilidades de consciência e de vida das próximas gerações.

Blanca Chancoso, dirigente quechua, assim o expressa:

Pachamama é vida, é como o ventre de nossa mãe, ela nos abriga, nos alimenta, nos dá trabalho, nela encontramos a alegria, por isso devemos cuidar dela, querê-la, porque é a vida em si mesma. Durante muito tempo a Pachamama foi maltratada, saqueada [...] pela voracidade do modelo econômico e hoje se encontra doente; mostra disso são as mudanças climáticas e os desastres naturais [...]. Hoje estamos em alerta [...] por não haver compreendido a dor da Pachamama. A Pachamama é um símbolo 
vivo, presente, parte do curso da vida, da ordem natural, do cosmos vivo e bio-ético. Este símbolo vivo apresenta uma forte relação parte-todo; indivíduo-comunidade; comunidade-mundo; mundo-cosmos. Trata-se de uma racionalidade complementar, que conhece a realidade vitalmente e não apenas representativamente (CHANCOSO, 2010, p. 8).

Sumak kawsay foi, então, ponto de partida para a busca de raízes do anseio por uma vida melhor, mais justa, equitativa, em harmonia com a natureza. Anseio que vínhamos vendo manifestado em inúmeras propostas de alternativas ao desenvolvimento com que vínhamos tomando contato através da obra de Boaventura de Souza Santos e de textos que relatavam experiências em toda a América Latina. Experiências que eram encontradas também na África, a partir do conceito de $U_{b u n t u^{22}}$.

\section{Aprofundando e expandindo a espiral}

Quanto mais nos aprofundávamos nesse conceito, a partir de textos, experiências, testemunhos, diálogos, mais fomos percebendo que sumak kawsay era também ponto de chegada. Era o que almejávamos como ideal de vida para nós e para noss@s filh@s e net@s.

Como encontrar caminhos para materializar essa proposta? Começamos a buscar conexões com outras pessoas, grupos, comunidades que manifestavam o mesmo propósito. Numa dessas andanças, nos deparamos com Maturana, inicialmente com seu texto "Conversações Matrísticas e Patriarcais", depois publicado como capítulo inicial do livro "Amar e Brincar, fundamentos esquecidos do humano", escrito em parceria com VerdenZoller. Em seguida, com o Instituto de Formação Matriztica. ${ }^{23}$

E aí começou uma outra tessitura. ${ }^{24} \mathrm{~A}$ descoberta da modernidadecolonialidade não como início, mas como aprofundamento de um modelo dominador, violento, excludente, que teve início não há 500, mas há aproximadamente 5.000 anos, com o advento do patriarcado.

A subjugaçãosupressão do feminino, que está presente desde então, não é só o cerceamento de mulheres reais, vivas, empíricas, mas também dos aspectos femininos da própria constituição dos homens, a anima, como postula Jung. A subjugação do feminino se deu ao mesmo tempo que a dominação da natureza, a Pachamama. E fundou um paradigma de dominaçãosupressão, que vem, desde então, estabelecendo, o diferente como inferior, anormal, demoníaco. Mais uma vez, é a perspectiva decolonial que nos dá as ferramentas 
necessárias para entender esse acontecido.

E, então, outra sincronicidade. $\mathrm{O}$ que as escavações e pesquisas recentes, da arquelogia e da arqueomitologia, vinham revelando sobre as sociedades do paleolítico superior, do neolítico e de algumas das civilizações mais antigas históricamente conhecidas, como a de Creta, encontravam profunda ressonância no sumak kawsay:

Foi em Creta que, pela última vez na história escrita, prevaleceu um espírito de harmonia entre mulheres e homens, como participantes iguais e jubilosos na vida. É esse o espírito que parece irradiar na tradição artística cretense, uma tradição que, nas palavras de Platon, é única em seu "deleite da beleza, da graça e do movimento" e em seu "desfrute da vida e proximidade da natureza" (EISLER, 2007, p. 76).

As evidências mostram que a riqueza cretense era investida prioritariamente em desfrutar uma vida harmoniosa e bela (ibid., p. 81).

Toda a vida era permeada por uma fé ardente na deusa natureza, fonte de toda criação e harmonia. Isto levava ao amor pela paz, ao horror pela tirania e ao respeito à lei (PLATON apud EISLER, 2007, p. 82).

De que modo, expandir nossa reflexão até um momento que ainda conhecemos como "pré-história", pode ajudar na desconstrução de subalternidades e na transformação pessoal e cultural que queremos operar?

Se a consciência da modernidadecolonialidade nos ajudou a perceber que há outras Histórias e muitas outras maneiras de escrever-viver a História, tomar consciência de que se o Sumak kawsay sobreviveu, não só a quinhentos, mas a cinco mil anos de dominação, pode se constituir em impulso para uma transformação real de nossa sociedade hoje.

Além disso, se descobertas arqueológicas nos dão a conhecer outras formas de organização social que privilegiam a cooperação, o respeito à dignidade de todos os seres, a conexão com a Natureza, formas que sobreviveram ao menos por vinte mil anos antes do surgimento do patriarcado, entendemos que nosso anseio por esse modo de vida não é apenas o sonho de um paraíso perdido, ou utopia que serve apenas como horizonte, mas nunca poderá ser realizada, como ao longo da história nos quiseram fazer crer.

Em seu livro, Acosta assim se manifesta após falar sobre o Sumak kawsay:

São palavras que cheiram a utopia... Pois é isso mesmo. Há que escrever todos os rascunhos possíveis de uma utopia que ainda será construída. Uma utopia que implica a crítica da realidade sobre princípios forjados no Bem Viver. Uma utopia que, por ser um projeto de vida solidário e sustentável, deve ser uma 
alternativa imaginada coletivamente, conquistada e construída politicamente, e executada democraticamente a todo momento e circunstância (ACOSTA, 2016, p. 198).

Hoje, o sistema de trocas ganha força nas vidas urbanas e entre estas e os espaços rurais, em várias partes da América Latina, e também em outras partes do mundo. Há um anseio de solidariedade social que pede pelos encontros, pela visibilidade, pela irrupção de outros significantes. ${ }^{25}$ Pela construção de outras linguagens, outras relações.

Há comunidades agroecológicas - agrovilas - que inventam cotidianamente outras formas de produzir, se relacionar, cuidar e educar suas crianças, jovens, idos@s.

Há, ainda, grupos que ocupam as cidades de outras formas. Grupos errantes, nômades, que usam a cidade sem se integrar às suas regras. São com frequência acusados pelos poderes estabelecidos de desestabilizar a ordem, por isso reprimidos como perigosos. De fato podem desestabilizar a ordem estabelecida, por mostrarem por suas vidas que um outro mundo é possível.

Utopias que permanecem. É este conflito entre um projeto que se impõe como global porque elimina ou desqualifica todos os outros e a utopia que permanece viva no modo de existir de povos nativos e no inconsciente coletivo, na ânsia por uma existência que inclua e harmonize.

A Humanidade não é uma comunidade de seres agressivos e brutalmente competitivos. Esses valores foram criados e acentuados por civilizações que favoreceram o individualismo, o consumismo e a acumulação agressiva de bens materiais - características que estão no gene da civilização capitalista. Já se demonstrou cientificamente a tendência natural dos seres humanos à cooperação. Trata-se, então, de recuperar e fortalecer estes valores e suas instituições ancestrais, complementando-as com outras que podem ser desenhadas e desenvolvidas a partir dos mencionados princípios de reciprocidade, redistribuição e solidariedade (ACOSTA, 2016, p. 192).

E continua:

Igualmente, os princípios feministas de uma economia voltada ao cuidado da vida, baseada em cooperação, complementariedade, reciprocidade e solidariedade, colocam-se na ordem do dia. São concepções relevantes para as mulheres e para a sociedade em seu conjunto. Como parte de um processo de construção coletiva do Bem Viver, exigem novas abordagens feministas em que se expliquem e cristalizem os conceitos de autonomia, soberania, dependência, reciprocidade e equidade (ibid., p. 192). 
Manter juntas a dúvida e a utopia significa pensar a possibilidade de um posicionamento ético-político-epistemológico que não exalte a dúvida pela dúvida, mas, querendo desfazer o vínculo entre conhecimento e disciplina que marcou o que Spivak denomina de violência epistêmica da modernidade, saiba se posicionar nos entrelugares ${ }^{26}$ polifônicos das vozes antes caladas, para falar com elas e a partir delas, nunca por elas.

A primeira consequência político-epistemológico-pedagógica deste modo de pensarser-aprender-ensinar é que afirmar uma verdade não tem como consequência imediata negar qualquer outra alternativa ou possibilidade, mesmo contraditória ou até divergente. Isto não nos lança num vale-tudo prático ou teórico que deita por terra qualquer princípio ou critério de valoração, mas exige que, acima de tudo, esteja a afirmação da vida, em todas as suas dimensões, como valor maior. ${ }^{27}$

\section{Arremates que se abrem em franjas}

Todos esses movimentos teóricopráticos têm em comum a percepção de que as relações entre os seres humanos e entre estes e a natureza podem e precisam tomar outro rumo: competição, dominação, violência, exclusão não são inerentes à natureza humana.

Nada está posto.

O caminho se faz ao caminhar.

A mudança de paradigmas requer uma expansão não apenas de nossas percepções e maneiras de pensar, mas também de nossos valores. Aliás, a questão dos valores é fundamental para a transformação que almejamos; é, de fato, sua característica definidora central. Enquanto o velho paradigma está baseado em valores antropocêntricos (centralizados no "homem"), o Bem Viver está alicerçado em valores ecocêntricos (centralizados na Terra, no Cosmos). É uma visão de mundo que reconhece o valor inerente a todo o existente. Todos os seres - vivos ou não-vivos - são membros de comunidades ecológicas ligadas umas às outras numa rede de interdependências. Quando essa percepção ecológica profunda torna-se parte de nossa consciência cotidiana, emerge um sistema de ética radicalmente novo, uma mudança em nosso modo de SER.

Os jogos de poder, sem dúvida, continuam. No entanto, há outro tipo de poder, um 
poder mais apropriado para o novo paradigma - poder como influência de e sobre. A estrutura ideal para exercer esse tipo de poder não é a hierarquia, mas a rede, que é também a metáfora central da eco-logia. A mudança de paradigma inclui, dessa maneira, uma mudança na organização social, na economia, nas estruturas de poder. Uma mudança de hierarquias para redes; de competição para cooperação; de devastação para cuidado.

É possível pensarmos - e reinventarmos, hoje - uma perspectiva não-agressiva, não violenta, não-excludente, para as relações intrapessoais, interpessoais, sociais, planetárias, cósmicas?

Esgarçar paradoxos.

Escancarar a diferença.

Colocar-se no meio, no entrelugar, onde nada está cristalizado e todas as possibilidades podem emergir.

Critérios de avaliação: as propostas - e sua materialização - promovem conexões, integrações, diálogos, ou continuam a fragmentar, excluir, separar?

\section{REFERÊNCIAS}

ACOSTA, A. O bem viver: uma oportunidade para imaginar novos mundos. São Paulo: Elefante, 2016.

AZIBEIRO, N.E. A criação de relações de saber, poder e prazer na vida e nos processos educativos: a experiência do FFMP-INCA, 1a., 2a. e 3a. turmas. 1994. 171f. Dissertação (Mestrado em Educação). Centro de Ciências da Educação, Universidade Federal de Santa Catarina, Florianópolis, 1994.

O Currículo que interessa às classes populares. Revista Percursos, FAED-UDESC, Florianópolis, v. 6, n. 1. 2005a. Disponível em: http://www.periodicos.udesc.br/index.php/percursos/article/view/1447. Acesso em: 26 out. 2018.

Em busca de uma perspectiva dialógica. Trabalho apresentado no Congresso Internacional Cotidiano: diálogos sobre diálogos. Disponível em cd-rom. Rio de Janeiro: UFF, $2005 b$.

. Educação Intercultural e Comunidades de Periferia: limiares da formação de educadores. 2006. 338 f. Tese (Doutorado em Educação) - Centro de Ciências da Educação, Universidade Federal de Santa Catarina, Florianópolis, 2006. 
. Ecologia do Corpo Coração Mente Espírito: uma jornada de autoconhecimento e cura. TCC. Izen-Itecne. Especialização em Psicologia Transpessoal. Florianópolis, 2016.

BHABHA, H. O local da cultura. Trad. Myriam Ávila, Eliana Lourenço de Lima Reis, Gláucia Renate Gonçalves. Belo Horizonte: Ed. UFMG, 1998.

CAPRA, F. A teia da vida. São Paulo: Cultrix, 1996.

CARVALHO, M. A. B. De frente para o Espelho: Ecopsicologia e sustentabilidade. 2013. 165 f. Tese (Doutorado) - Centro de Desenvolvimento Sustentável, UnB, Brasília, 2013.

CHANCOSO, B. "El Sumak Kawsay desde la visión de la mujer" in América Latina en Movimiento. Alternativas civilizatorias: los viejos nuevos sentidos de la humanidad, Número 453, Año XXXIV, II Epoca, 7-9, mar. 2010.

DELEUZE, G. Os intelectuais e o poder. In: FOUCAULT, M. Microfisica do poder. Organização e tradução de Roberto Machado. Rio de Janeiro: Graal, 1979.

. A Dobra: Leibnitz e o Barroco. Campinas: Papirus, 1991.

EISLER, R. O cálice e a espada: nosso passado, nosso futuro. Trad. Tônia Van Acker. São Paulo: Pallas Atena, 2007.

FOUCAULT, M. Microfisica do Poder. Organização e tradução de Roberto Machado. Rio de Janeiro: Graal, 1979.

FREIRE, P. Pedagogia do Oprimido. 4. ed. Rio de Janeiro: Paz e Terra, 1977.

GARCIA, R. L. Método: pesquisa com o cotidiano. Rio de Janeiro: DP\&A, 2003.

GROF, S. The Stormy Search for the Self: a Guide to Personal Growth Through Transformational Crisis. (A tempestuosa busca do ser). J. P. Tarcher, 1990.

. The Cosmic Game: Explorations of the Frontiers of Human Consciousness. (O Jogo Cósmico: Explorações das Fronteiras da Consciência Humana). SUNY Press, 1998.

GUDYNAS, E. Tensiones, contradicciones y oportunidades de la dimension ambiental del Buen Vivir. In: FARAH, I.; VASAPOLLO, L. Vivir bien: ¿Paradigma no capitalista? La Paz: cides-umsa, 2011. p. 231-246.

MORIN, E. A cabeça bem feita: repensar a reforma, reformar o pensamento. Trad. Eloá Jacobina. Rio de Janeiro: Bertrand Brasil, 2000.

PLATON, N. Crete. Geneva: Nagel Publishers, 1966. (Archeologia Mundi Series).

REPÚBLICA DEL ECUADOR. Constituciones de 2008. Disponível em: 
$<$ http://pdba.georgetown.edu/Constitutions/Ecuador/ecuador08.html >. Acesso em: 20 out. 2012.

SANTIAGO, S. O entre-lugar do discurso latino americano. In: Uma literatura nos trópicos. São Paulo: Editora Perspectiva, 1978, p. 11-28.

WALSH, C. Interculturalidad, Estado y sociedad. Luchas (de)coloniales de nuestra época. Quito: Abya Yala, 2009.

. Pedagogías decoloniales: prácticas insurgentes de resistir, (re)existir y (re)vivir. Tomo I. Quito, Ecuador: Ediciones Abya-Yala, 2013.

WEIL. P. A Consciência Cósmica, Introdução à Psicologia Transpessoal. 2. ed. Petrópolis, RJ: Vozes, 1972.

WILBER, K. O espectro da consciência. São Paulo: Cultrix, 1989.

${ }^{1} \operatorname{Prof}^{\mathrm{a}} \mathrm{Dr}^{\mathrm{a}}$ Aposentada - Centro de Ciências Humanas e da Educação (FAED)/Universidade do Estado de Santa Catarina (UDESC). Terapeuta Transpessoal. nadirazibeiro@gmail.com

2 "Uma teoria é como uma caixa de ferramentas" (DELEUZE, 1979, p.71).

${ }^{3}$ Foucault denomina arqueologia e genealogia a escavação de discursos e outros dispositivos (conjuntos articulados de discursos e práticas) que produzem saber-poder. Tenho escavado as múltiplas rupturas que produziram as subalternizações, gerando as diferenças que ainda hoje são lidas e vividas como hierarquizações. "Enquanto a arqueologia é o método próprio à análise da discursividade local, a genealogia é a tática que, a partir da discursividade local assim descrita, ativa os saberes libertos da sujeição que emergem desta discursividade" (FOUCAULT, 1979, p. 172).

${ }^{4}$ Ver AZIBEIRO, 2006, p. 19.

${ }^{5}$ Para Freire (1977, p. 93) "o diálogo é uma exigência existencial” [...] “O diálogo é o encontro de pessoas, mediatizadas pelo mundo, para pronuncia-lo, não se esgotando, portanto, na relação eu-tu" [...] "É um ato de criação". (grifos no original). Morin entende o conceito de dialógico como a possibilidade de interação e interrelação de múltiplas perspectivas, inclusive as antagônicas, que nem se fundem, nem se excluem, nem se dominam ou se submetem, mas levam a entendimentos plurais e provisórios (2000, p. 206 apud AZIBEIRO, 2006, p. 29).

${ }^{6}$ Até o início da década de 1970, o ensino fundamental se organizava como primário (os anos iniciais) e ginásio (os quatro anos finais).

${ }^{7}$ Com o símbolo “@” quero indicar simultaneamente os gêneros feminino e masculino. Ao invés de verter o gênero dos substantivos (e respectivos complementos nominais) no masculino, que seria o gramaticalmente correto, vimos utilizando propositalmente esta forma gráfica, para levantar a questão - política e cultural - do sexismo de nossa linguagem, que transforma o masculino no genérico, diluindo nele o feminino.

${ }^{8}$ Já o afirmei em outras ocasiões: "não tenho medo de beber em várias fontes; isso só é perigoso se ficarmos repetindo automaticamente modismos ou frases de efeito, sem os reelaborarmos a partir de nossa própria experiência e conhecimento" (Cf. AZIBEIRO, 1994, p. 104; 2006, p. 25).

${ }^{9}$ Ver AZIBEIRO, 2005; 2006; 2012.

${ }^{10}$ Desconstrução de subalternidades e mudanças paradigmáticas. Texto publicado na Revista Pedagógica da UnoChapecó.

${ }^{11}$ Carta da Terra; Cultura de Paz; Pedagogia da Cooperação; Transformação de Conflitos.

12 Preâmbulo. Constituição do Equador. 2008.

${ }^{13}$ Ver AZIBEIRO, 2006, p. 75ss.

${ }^{14}$ Abya Yala é a denominação de nativos para o continente americano em referência ao período pré-colonial. Essa citação de Walsh, encontrei em meus alfarrábios, mas não consegui mais localizar o texto do qual foi

Revista Interinstitucional Artes de Educar. Rio de Janeiro, V. 4 N. 3 - pag 496-512 (out/2018 - jan/2019) 
extraída. Trabalhei bastante com Walsh e em vários textos ela escreve sobre Interculturalidade, Pedagogias Decoloniais e Sumak Kawsay. Ficam especialmente como referência os Livros por ela organizados em 2009 e 2013.

${ }^{15}$ ACOSTA, Alberto. O bem viver: uma oportunidade para imaginar novos mundos. São Paulo: Elefante, 2016, p. 69. Ver ainda, a este respeito: GUDYNAS, Eduardo; ACOSTA, Alberto. El buen vivir más alla del desarollo. In: Quehager. Equador: Desco, 2011, p. 78; QUIJANO, Aníbal. América Latina: hacia un nuevo sentido histórico. In: LEÓN, Irene (org.) Sumak kawsay / Buen vivir y cambios civilizatorios. 2. ed. Quito: FEDAESP, 2010, p. 55-73; FARAH, Ivonne; VASAPOLLO, Luciano. (coords). Vivir bien: ¿paradigma no capitalista? Bolivia: CIES-UMSA; Sapienza Universitá di Roma; Oxfam, 2011.

${ }^{16}$ Disponível em: <https://rosaluxspba.org/wp-content/uploads/2017/06/Bemviver.pdf>. Acesso em: 08 out. 2018.

${ }^{17}<$ https://racismoambiental.net.br/2018/07/22/vandana-shiva-aposta-no-ecofeminismo/>.

${ }^{18}$ Cf. AZIBEIRO, 1994, p. 87.

${ }^{19}$ Ponto de Mutação; A Teia da Vida; Sabedoria Incomum.

20 Ver AZIBEIRO, 1994, p. 71ss.

${ }^{21}$ Cf. AZIBEIRO, 1994; 2006; 2016.

${ }^{22}$ Ubuntu, na língua zulu, significa ser com os outros. Ubuntu ressalta a importância do acordo ou consenso. A cultura tradicional africana, ao que parece, tem uma capacidade quase infinita para a busca do consenso e da reconciliação (TEFFO, L. J. The concept of Ubuntu as a cohesive moral value. Pretoria: Ubuntu School of Philosophy, 1994).

$23<$ https://www.facebook.com/Matriztica/ $>$.

${ }^{24}$ Maria Tereza de Queiroz Piacentini, catarinense, professora de Inglês e Português, revisora de textos e redatora de correspondência oficial, entende que a grafia correta seria tecitura, em se tratando de seu uso no sentido de "trama, urdidura". A grafia com dois "ss" se justificaria ao se pensar numa "composição musical" (ver < http://www.linguabrasil.com.br/>). Compartilho da escolha explicitada por Regina Leite Garcia do movimento de aproximação entre ciência e arte (2003, p. 13). Considerando a trama de sentidos e de relações que se tece nas relações sociais como uma modulação (DELEUZE, 1991, p. 36), uma articulação de tons culturais e sociais, continuamente se reformulando, optei por manter a grafia tessitura.

${ }^{25}$ Para Saussure, o significante constitui a forma (imagem acústica) que um significado (conceito) assume em cada contexto específico.

${ }^{26}$ O termo entre-lugar foi usado por Silviano Santiago (1978) e para as tradutoras de Bhabha (1998, p.10) mostrou-se o mais adequado para significar a expressão in-between. Assim Homi Bhabha se refere aos "momentos ou processos que são produzidos na articulação de diferenças culturais" (1998, p. 20). São os interstícios, o liminar, o contingente, a passagem: "fornecem o terreno para a elaboração de estratégias de subjetivação - singular ou coletiva - que dão início a novos signos de identidade e postos inovadores de colaboração e contestação" (1998, p.20). É o espaço de fronteira, o além. É o inter - "o fio cortante da tradução e da negociação, o entrelugar - que carrega o fardo do significado da cultura, onde torna-se possível evitar a política da polaridade e emergir como os outros de nós mesmos" (BHABHA, 1998, p.69). Entendemos, então, por entrelugares, os espaços/tempos liminares, potencialmente inovadores, que intervêm para transformar o próprio cenário de articulação (BHABHA 1998, p. 228). A um tempo um lugar (espaço geográfico) e um nãolugar (espaço virtual em que tudo é possível e nada realizável). É o limiar, a fronteira: que une, que separa, que abarca e delimita, que abre horizontes e restringe possibilidades. É o espaçotempo de encontro e de passagem, que possibilita a emergência do múltiplo, do polifônico, da diferença - desconstruindo-se enquanto estereótipo e enquanto subalternização e reconstruindo-se como possibilidade de ressignificação da história, do cotidiano, das relações.

${ }^{27}$ Ver a este respeito AZIBEIRO, 2006, p. 337-8. 